\title{
Application of Electromagnetic Method for Mineral Prospecting in Al-Bayda Area, Yemen
}

\author{
Fitian R. Al-Rawi, \\ Ahmed S. Al-Gabery* and Mohamed S. Mustafa \\ Geological Survey and Mineral Resources Board, Ministry of Oil \& \\ Mineral Resources, P.O Box 297 Al- Tahrir, and \\ * Department of Earth and Environmental Sciences, \\ Faculty of Science, Sana'a University, Sana'a, Yemen
}

Received: 15/3/2004

Accepted: 5/3/2006

\begin{abstract}
An electromagnetic field survey using frequency domain method is conducted at Al-Bayda area (Jabel Mabel) for the purpose of mineral prospecting. An electromagnetic map is drawn from field measurements that are carried along eleven profiles. Profile length is $1300 \mathrm{~m}$ with a distance of $100 \mathrm{~m}$ between them, and with a station interval of $25 \mathrm{~m}$.

Electromagnetic curves are constructed from the field data. These are interpreted qualitatively to define the local buried conductor zones and quantitatively to estimate the depths of these sources through using Scintrex diagrams. These depths are found to be ranging between (30-66) $\mathrm{m}$. Most of the source bodies have dip mostly of $30^{\circ}$ SE. The conductance is also estimated and its values are between (360) Siemens.
\end{abstract}

Keywords: Electromagnetic, Mineral Prospecting, Al-Bayda, Jabel Mabel, Yemen.

\section{Introduction}

The electromagnetic method has been in use for a long time for mineral prospecting. The variations of electromagnetic field observed through the measurements of secondary electromagnetic fields at or over an area are reflecting the various conductivity parameters that are causing particular anomaly. This 
method is useful in the determination and detection of faults or shear zones and gives information about subsurface geology.

Electromagnetic measurements are performed either in the frequency domain (FEM) or in the time domain (TEM). Instruments for FEM are designed to perform investigations for mining engineering and ground water prospecting. TEM measurements are conventionally designed for deep targets, but recently there are instruments that can be used to explore shallow sources (20-500 m) (Meeks 1992). Electromagnetic methods can in principle be used in a profiling mode and in a sounding mode. In horizontal profiling, lateral variations in the conductivity to a certain depth can be studied, while electromagnetic sounding is used to determine vertical variations of the conductivity.

Scintrex has developed a transmitter and receiver that can be used in mineral prospecting of massive sulphide ore bodies, detection of faults and to delineate sand and gravel deposits. Besides, it can be used for ground water exploration and other geotechnical purposes (Scintrex manual 1988). Profiling method has been used in the present study for the purpose of mineral prospecting and delineation of fault zones.

The electromagnetic prospecting systems were developed in North America and Scandinavia, particularly Canada and Sweden. They proved to be successful in the search for massive sulphide deposits (Ward 1967). Theoretical studies concerning the application of these methods have been presented (Negi 1967, Roy 1970, Kamenetisky and Timofeev 1978). Negi (1967) showed that under favorable conditions an ore body with conducting cover would show up better than an uncovered one. The response of a target-overburden system will always fall progressively with overburden conductivity (Roy 1970).

Oristaglio and Hohmann (1984) used the two-dimensional models to simulate electromagnetic surveys over a thin conductor embedded in a half-space and with an overburden. Firstly, the geometric features of the model mainly control the pattern of diffusion and at a later time, the current concentrates at the center of the thin conductor that produces the characteristic crossover and peaked anomalies in the surface profiles of the vertical and horizontal electromotive force. Others evaluated the magnitude of the anomalous response as a function of delay time and frequency through the use of a two-dimensional theory of vertical plate like targets (Edwards 1988). Spies (1989) has used electromagnetic sounding methods to determine depth of burial and the average conductivity of the overlying section.

In this paper, measurements of the electromagnetic data have been carried out in Al-Bayda area (Jabel Moabel) within Al-Bayda Governorate, where metavolcanic rocks, post tectonic gabbro and alteration zones characterize this area. 
This method is used to gain information about the distribution of mineralized zones in the area and then to determine their depths, dips and conductance, in addition to any structural features.

\section{Geologic Setting of the Area}

The geology of Al-Bayda area is a part of the Precambrian basement complex of Yemen (Windley et al., 1996). The complex in Al-Bayda is differentiated into two belts, namely, the Al-Sawadia infracrustal and Al-Bayda suparcrustal belts.

The Al-Bayda belt forms a NE-SW trending zone separated from the adjacent Al-Sawadia belt by a major NE-SW thrust with a mylonitic foliation steeply dipping toward the NW. This belt consists of mélange blocks and matrix that are affected by cataclasis and low grade green schist metamorphism. The mélange blocks comprise gneissic and migmatitic infracrustal blocks pillowed, spilitic metavolcanic, metagabbro and ophiolitic serpentinite blocks and island arc metavolcanic blocks. The mélange matrix is composed of mudstone, slates and phyllites (Al- Khirbash et. al., 2000).

The studied area belongs to Al-Bayda belt, which is part of Al-Bayda island arc terrain. The geology of the study area comprises two main rock types the post tectonic gabbro, and the metavolcanic rocks, and both are affected by alteration meso-epithermal, (Fig. 1). The post tectonic gabbro occurs, as elongated massive units with no sign of deformation except on latter faulting. These rocks cover a huge region that extends to the east and west of the studied area.

The metavolcanic rocks are the oldest rocks in the studied area. Their occurrences are well exposed in the central part of the area (Fig. 1). They have a $\mathrm{N}-\mathrm{S}$ trending zone and are separated from the post-tectonic gabbro by a major $\mathrm{N}-\mathrm{S}$ trending fault and secondary fault trending NE-SW.

In general, lithological alteration and sulphide mineralization features appear as nearly parallel zones. They are clearly shown on fault sides and along their strike due to, which are of meso-epithermal hydrothermal solutions.

\section{Field Surveys}

The study area is located at about $40 \mathrm{~km}$ from Al-Bayda city. The total area is about $1.3 \mathrm{~km}^{2}$. The topographic survey was carried out through the use of GPS and with compass and theodolite. The survey included (11) profiles with a length of $1300 \mathrm{~m}$ each. The separating distance is $100 \mathrm{~m}$ between profiles with a $25 \mathrm{~m}$ space interval between stations. The direction of the profiles is $50^{\circ} \mathrm{NW}$, an orientation normal to the local geologic strike (Fig. 2). 


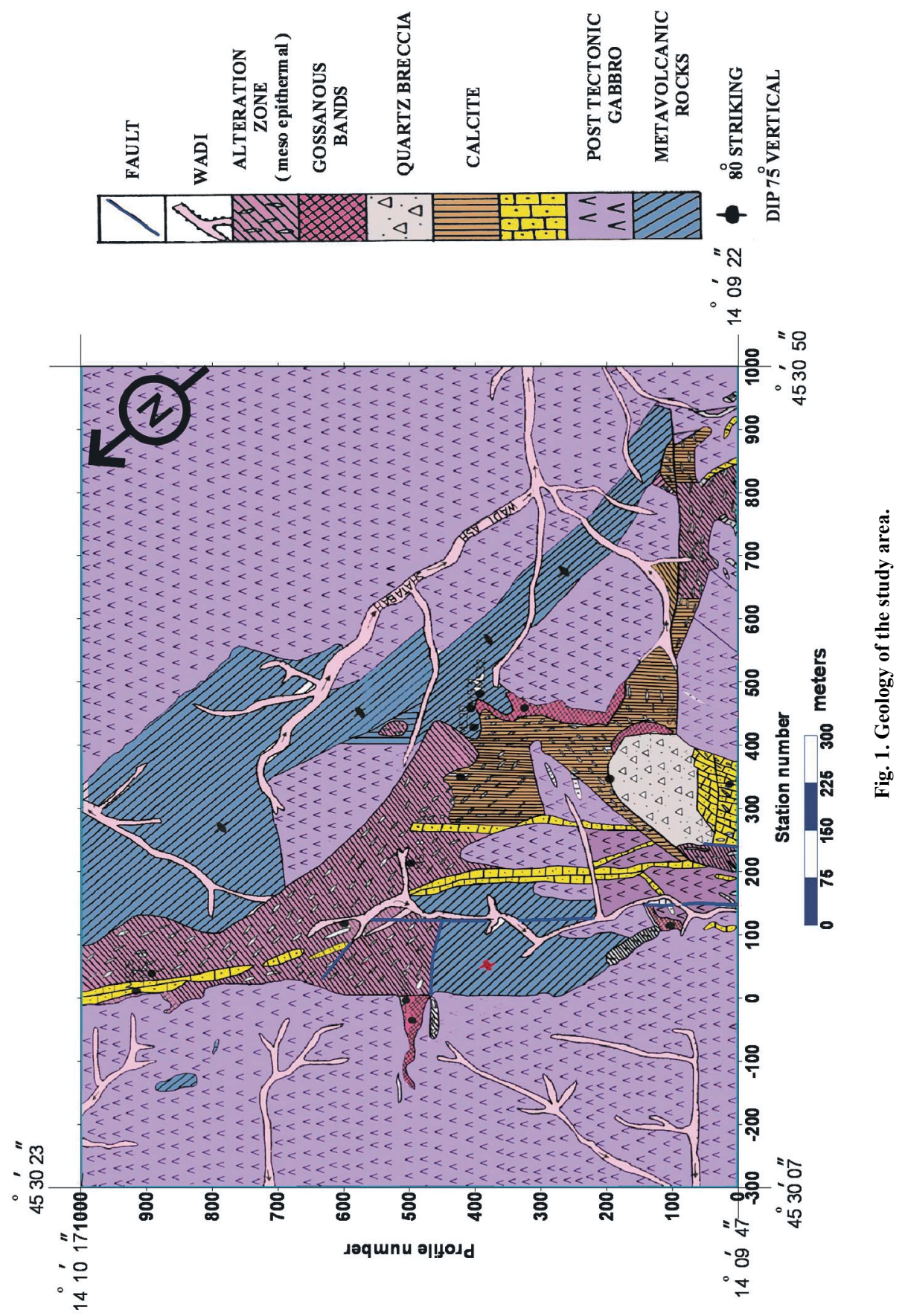




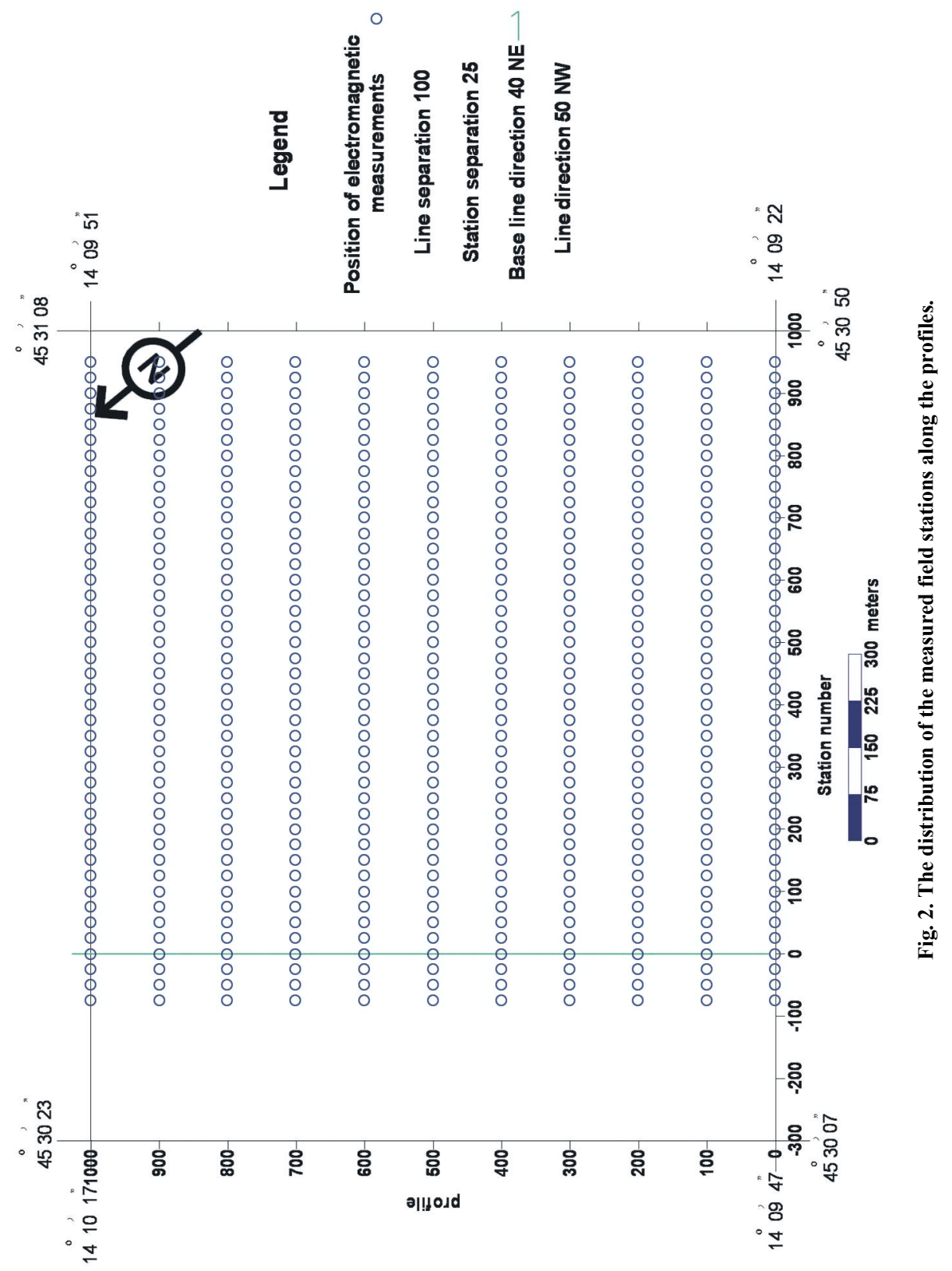


The electromagnetic survey for the area was carried out by using IGS-EM - 4 Genie Horizontal Loop Electromagnetic Receiver(HLEM) with TM-2 Electromagnetic Transmitter. The receiver measured the ratio of the magnetic amplitude at one or pair of frequencies (Johnson and Doborzynski 1986), i.e. the amplitude from signal channel to the amplitude from the reference multiply by the factor adjusting for different transmitter moment. The transmitter emits a sinusoidally varying current at a specific frequency (Klein and Lajoie 1992). The system has nine frequency pairs. Genie frequency reading of 337.5/112.5, $1012.5 / 112.5$ and $3037.5 / 112.5 \mathrm{~Hz}$ are used. Coil separation of $100 \mathrm{~m}$ and readings are taken at an interval of $25 \mathrm{~m}$ along lines having $1000 \mathrm{~m}$ length and striking $40^{\circ} \mathrm{NE}-\mathrm{SW}$. Results of the survey are also presented as maps for the frequency pairs and off set/stacked profiles.

\section{Interpretation of Electromagnetic Maps}

The three frequency pairs are used in order to discriminate between a conductive zone from other geologic noise sources, like overburden. The selection of the three frequency pairs is based upon the requirement of quantitative interpretation because at least three pairs should be used to apply the diagrams given by Scintrex. The three pairs represent shallow, medium and deep penetration which provide the information that is needed for estimation of various source parameters. The 3037.5/112.5 frequency pair gives the widest conductance range 14-300 Siemens and therefore it is used as a standard frequency. The frequency pair of 1012.5/112.5 has a range of 45-290 Siemens, and for frequency pair of 337.5/112.5 has 50-275 Siemens. If a response is seen from the application of frequency pair of 337.5/112.5, then the target is considered to be quite conductive (Scintrex Manual 1988). Parasnis (1972) indicated the penetration depth is decreased with increase in frequency, i.e. using higher frequency pairs well reflect shallow sources, while low frequency pairs reflect deep sources.

The electromagnetic data responses for the three frequency pairs are presented in Fig. ( 3 a,b and c). These maps show that the responses are clearly exhibited in the presence of a negative anomaly (A), which is associated with alteration zone and in turn is probably caused by shallow sources. The presence of closed contours in anomaly (A) is related to a fault separation between the boundary of the alteration zone and the metavolcanic rocks. The small closed negative anomalies F, G, H, I and J are shown only in Fig. (3c), and they are not clear in Fig. ( 3 a and b) except anomaly J. These are associated with the exposed post tectonic gabbro and they represent a possible extent of anomaly (A). Two negative anomalies are revealed in Fig. ( $3 \mathrm{~b}$ and c), one (anomaly C) associated with the post tectonic gabbro, Calcareous-dolomitic marble and alteration zone, trending NNE-SSW. The other anomaly (D) overlies the post tectonic 


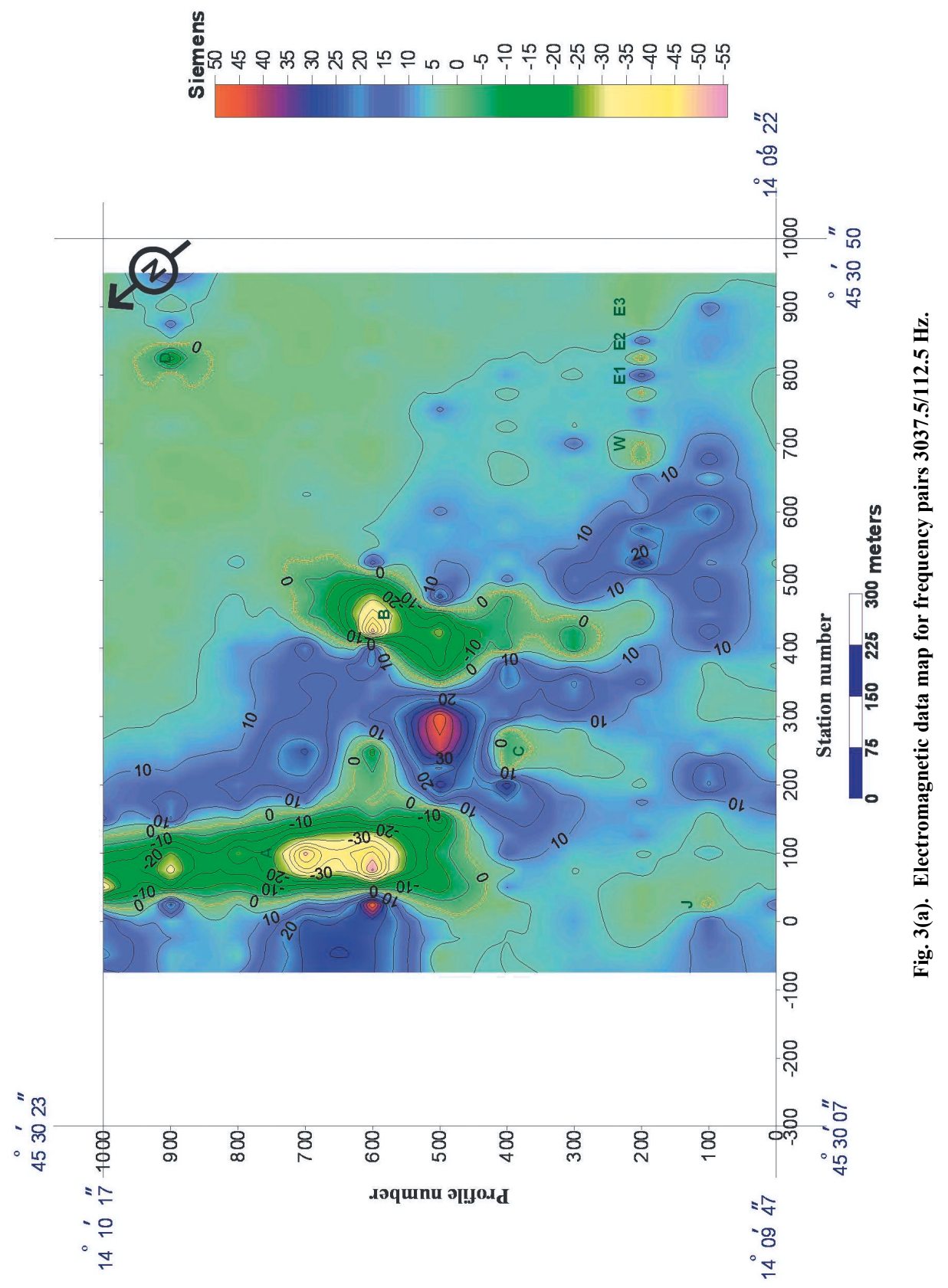




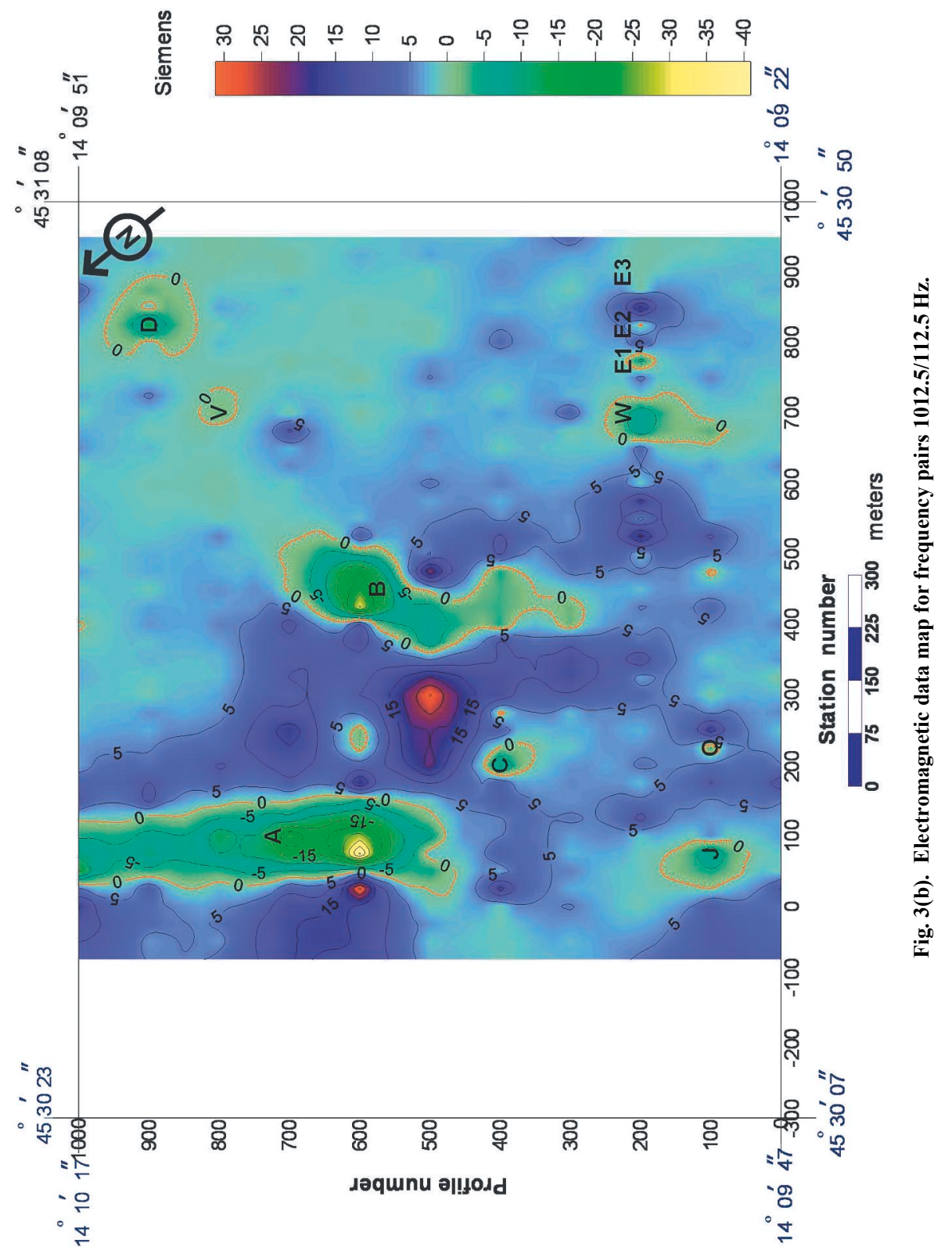


Application of Electromagnetic Method for Mineral...

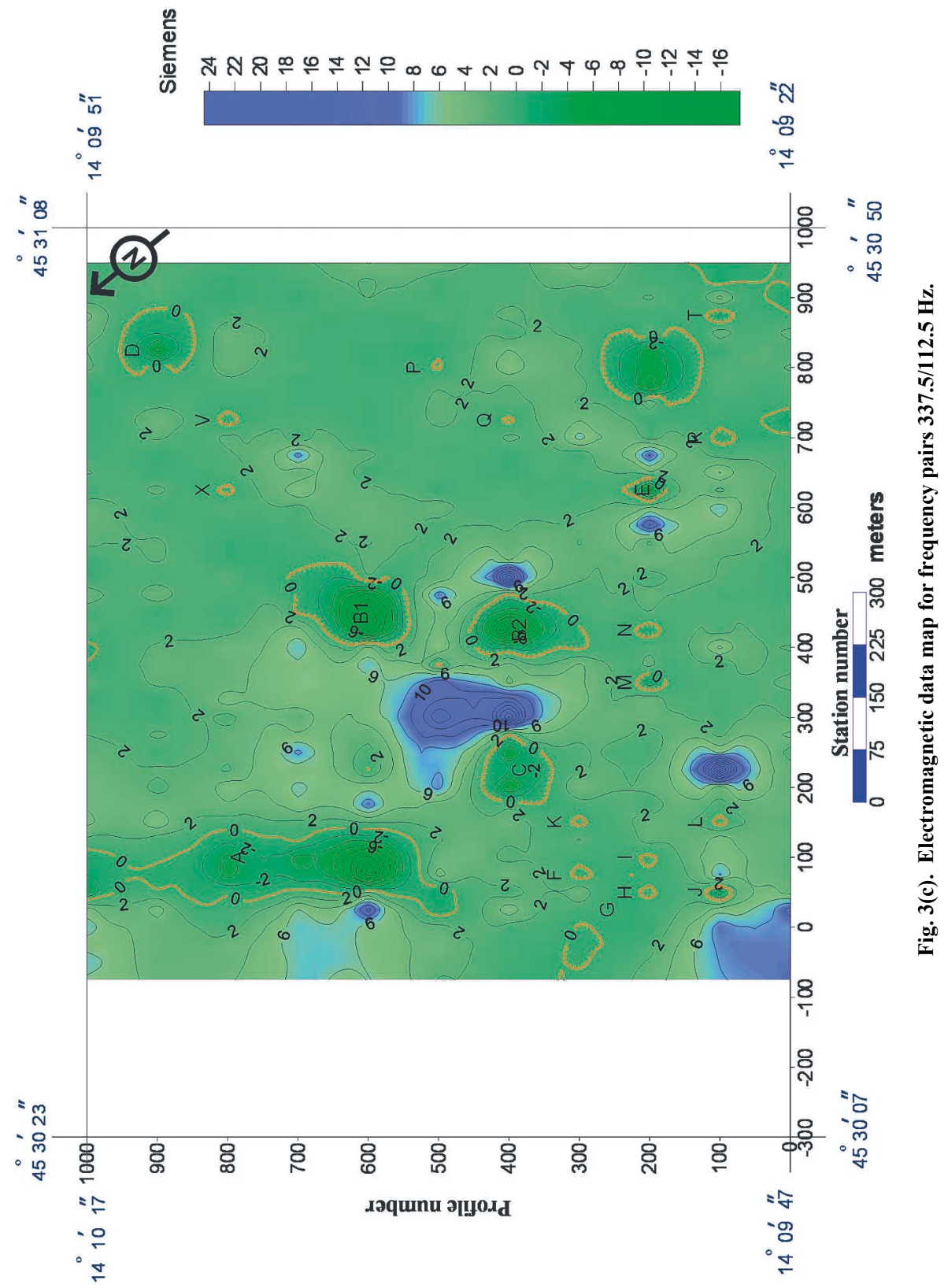


gabbro. The negative anomaly (anomaly B) to the east of anomaly (A) Fig. (3 a and b) is probably caused by shallow conductor source. This anomaly is associated with the metavolcanic rocks, alteration zone and post-tectonic gabbro. Such anomaly (Fig. 3c) may be separated by a narrow positive anomaly area between profiles 400 and 500. The anomaly is divided into two negative anomalies B1 and B2 which have a NE-SW trend.

Many small negative anomalies, K, L, M, N, Q, P, V and X are shown in Fig. (3c) which are not clear in Fig. ( $3 \mathrm{a}$ and $3 \mathrm{~b}$ ). These may be deeper conductor and cannot be reached by using frequency pairs 3037.112.5 and 1012.5/112.5. Anomalies $\mathrm{M}$ and $\mathrm{N}$ are most probably representing part of the anomaly B2. Anomalies Q, P, V appear as small rings associated with post tectonic gabbro in Fig. (3c) and the same for anomaly $\mathrm{V}$ which may also be due to the same source, Fig. (3b).

The negative anomaly (W) in Fig. ( 3 b) is not so clear as on Fig. ( 3 a). This is due to the different depths of penetration between the two frequency pairs, 1012.5/112.5 and 3037.5/112.5. The same thing is not found in Fig. (3 c). This may be due to shallow conductor and cannot be reached by using frequency 337.5/112.5. The negative anomaly (E) is more obvious in Fig. (3 c). This anomaly is depicted as small circular anomalies, E1, E2 and E3 Fig. (3 a and b). Also anomalies Z, R, T, Y are shown as small circular anomalies and appear as a result of the different depths of penetrations that have been reached by various frequency pairs.

\section{Quantitative Interpretation}

A series of interpretation diagrams for Scintrex SE-88 Genie moving EM system have been utilized as an aid to the interpretation of Genie electromagnetic surveys which are based upon the experimental results. These diagrams are used to derive the dip, depth, thickness and conductance of source bodies. The dip direction is easily determined since the positive peak on the hanging wall side is larger than the positive peak on the foot wall side. Then, dip is determined by measuring the ratio of positive peaks on the Genie profiles at two or three frequency pairs and fitting them on one of the three families of curves (Scintrex Manual 1988). The ratio of depth to coil separation (H/L) is known once the best family of dip curves is found. The depth to current axis is then determined by multiplying the coil separation (L) by the indicated (H/L) ratio. The conductance is interpreted by using the appropriate family of curves, taking into consideration the rules of conductance type with peak of ratio responses. The procedures are easily applied to the profiles, 300, 400, 500, 600, 700, 800, 900, and 1000, while it is impossible to apply to profiles 0,100 , and 200 because they do not have clear negative anomalies. 

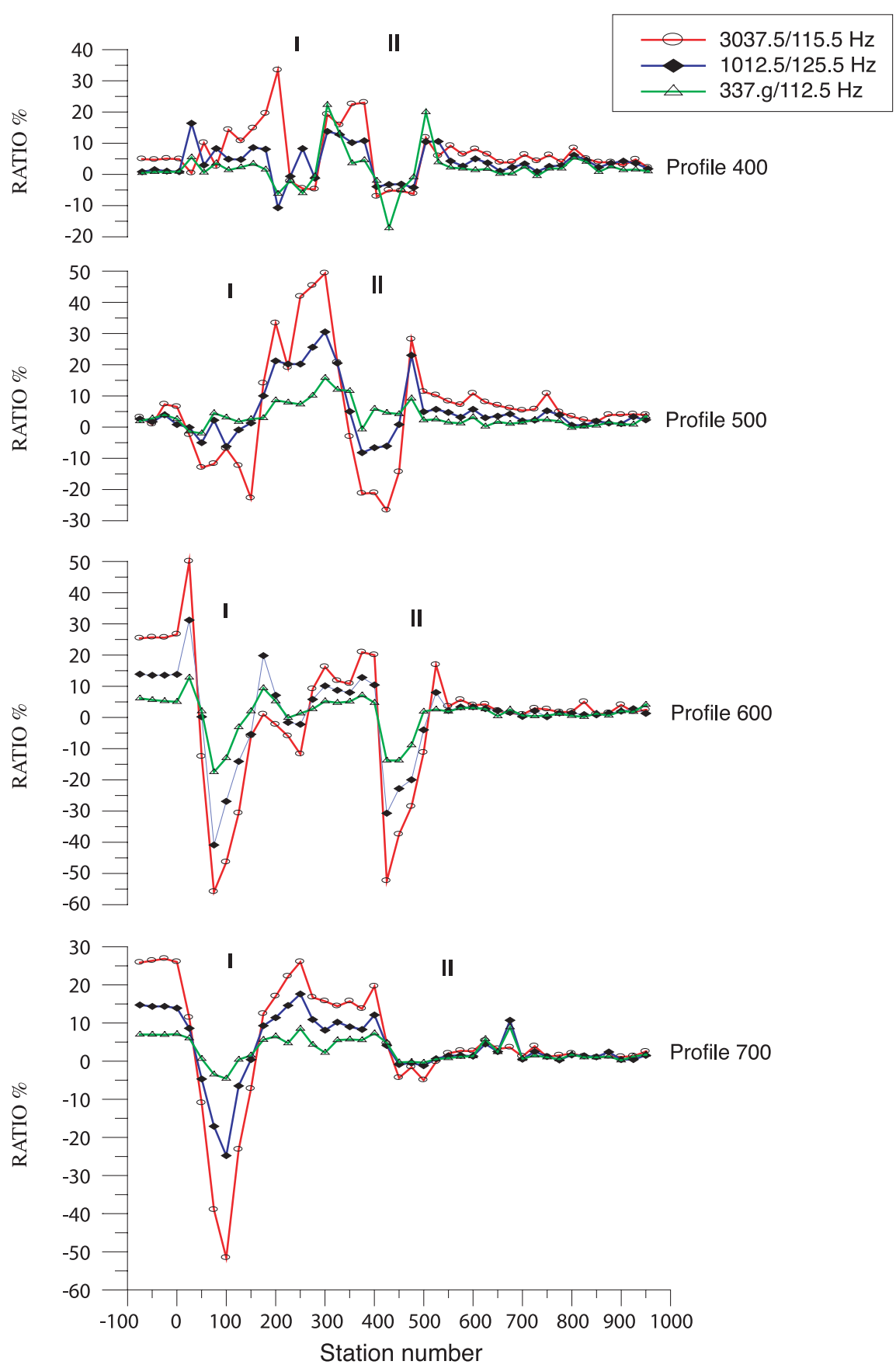

Fig. 4. Examples of electromagnetic profiles (along $400,500,600,700$ ) that were used in the quantitative interpretation. 
The results obtained from the interpretation of the electromagnetic profiles are presented in Table 1. These results include source body dip, depth of burial and the values of conductance. Figure (4) shows examples of the profiles used in the interpretation. From the obtained values as shown in Table (1), it is obvious that the depth of burial is gradually decreasing towards the NW. Most of the source bodies have a dip of about $30^{\circ} \mathrm{SE}$. The range of conductance is from 3 Siemens to 60 Siemens.

Table 1. The final results obtained from the calculations concerning the various sources parameters of the electromagnetic field.

\begin{tabular}{|c|c|c|c|c|c|c|c|}
\hline $\begin{array}{c}\text { Profile } \\
\text { number }\end{array}$ & $\begin{array}{c}\text { Depth } \\
(\mathbf{m})\end{array}$ & $\begin{array}{c}\text { Dip } \\
(\mathbf{d e g})\end{array}$ & $\begin{array}{c}\text { Conductance } \\
\text { (Siemens) }\end{array}$ & $\begin{array}{c}\text { Thickness } \\
(\mathbf{m})\end{array}$ & $\begin{array}{c}\text { Depth } \\
(\mathbf{m})\end{array}$ & $\begin{array}{c}\text { Dip } \\
\mathbf{( d e g})\end{array}$ & $\begin{array}{c}\text { Conductance } \\
\text { (Siemens) }\end{array}$ \\
\hline 300 & 66.7 & $30 \mathrm{SE}$ & 13.75 & 40 & & & \\
\hline 400 & 59 & $30 \mathrm{SE}$ & 8.15 & & 69 & $45 \mathrm{NW}$ & 3 \\
\hline 500 & 40 & $30 \mathrm{SE}$ & 3.15 & & 53 & $30 \mathrm{NW}$ & 9.38 \\
\hline 600 & 50 & $30 \mathrm{NW}$ & 18.6 & & 43.5 & $45 \mathrm{NW}$ & 12.5 \\
\hline 700 & 40.7 & $30 \mathrm{SE}$ & 60 & & & & \\
\hline 800 & 45.9 & $45 \mathrm{SE}$ & 32.5 & 40 & & & \\
\hline 900 & 33 & $45 \mathrm{NW}$ & 4.5 & & & & \\
\hline 1000 & 50 & $30 \mathrm{NW}$ & 32.5 & 40 & & & \\
\hline
\end{tabular}

\section{Conclusion and Discussion}

The electromagnetic anomalies are concentrated over the western and central parts of the area. They are trending in NW-SE direction and are caused by shallow sources embedded in the basement rocks beneath the exposed rock units at the surface. In addition, there are possible deep sources in the eastern side of the area. Any drilling for mineral prospecting should be along the two main zones defined by this method and extension of drilling should be towards the deeper sources in the eastern part.

\section{References}

Al-Khirbash, S.M., Shawki, S., Maher, A.T. and Mohammed, A.S. (2000) Geology of Precambrian basement complex, Al-Bayda Governorate, Yemen, Fac. Sci. Bull., 13: 43-72.

Edwards, R.V. (1988) Two-dimensional modeling of towed in-line electromagnetic system: The optimum time delay or frequency for target resolution, Geophys., 53 (6): 846-853.

Johnson, I.M. and Doborzynski, Z.B. (1986) A novel ground electromagnetic system, Geophys., 51 (2): 396-409. 
Klein, J. and Lajoie, J.J. (1992) Electromagnetic prospecting for minerals, In: Practical Geophysics II for Exploration, Geologist, Compiled by Richard Van Blaricom, Northwest Mining Association.

Kamenetisky, F.M. and Timofeev, F.M. (1978) Negative electromagnetic screening, Izv. Earth Phys., 14: 226-280.

Meeks, J.A.C. (1992) Electromagnetic Methods in Ground Water Exploration, Course presented to geophysicists of general department of hydrology (Unpublished).

Negi, J.G. (1967) Electromagnetic Screening Due to a Disseminated Spherical Zone Over a Conducting Sphere, Geophys., 32: 69-87.

Oristaglio, M.L. and Hohmann, G.W. (1984) Diffusion of Electromagnetic Fields in a Twodimensional Earth: A finite difference approach, Geophys., 49: 870-894.

Parasnis, D.S. ( 1972) Principles of Applied Geophysics, Chapman and Hall, 214 p.

Roy, A. (1970) On the Effect of Overburden on Electromagnetic Anomalies, A review, Geophys., 14: $226-280$.

Scintrex Manual (1988) Operation Manual of TM-2 Genie/Horizontal Loop, Portable Electromagnetic.

Spies, B.R. (1989) Depth Investigation in Electromagnetic Sounding Methods, Geophys., 54: $872-885$.

Ward, S.H. (1967) The Electromagnetic Method in Mining Geophysics. Soc. of Expl. Geophys., 2: $224-272$.

Windley, B.F., Whitehouse, M.J. and Babattat, M.A. (1996) Early Precambrian Gneiss Terranes and Pan-African Island Arcs in Yemen: Crustal Accretion of the Eastern Arabian Shield, Geology, 24: 131-134. 
تـطبيق طريقة الكهرو مغنطيسية للتنقيب عن المعادن في منطقة

$$
\text { البيضاء - اليمن لزنيفن }
$$

فتيان رشيد الر اوي ، و أحمد سفيان الجابري"، و محمد شمس الدين

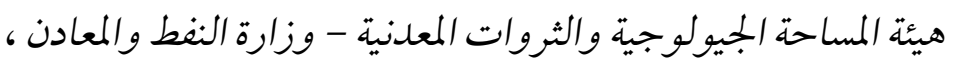

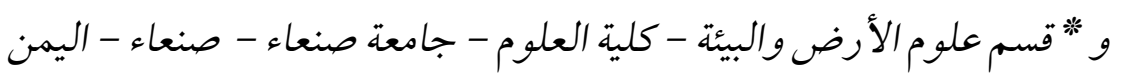

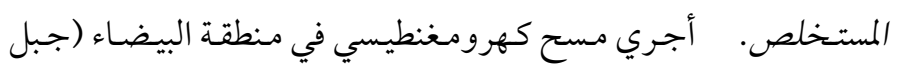

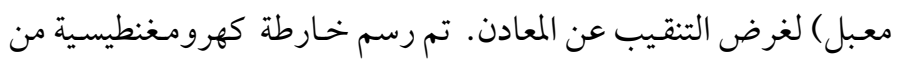

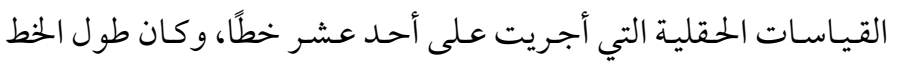

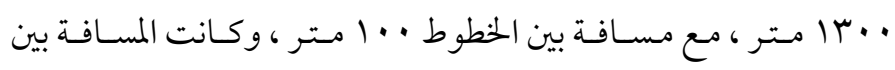
محطات القياس على كل خط هبمترا.

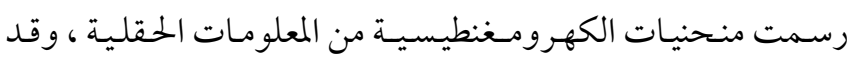

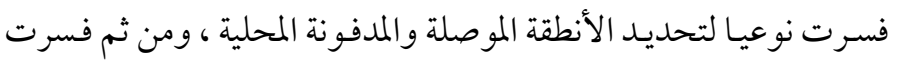

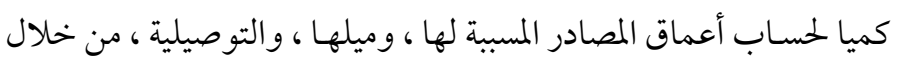

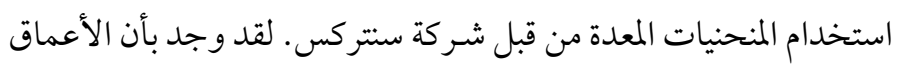

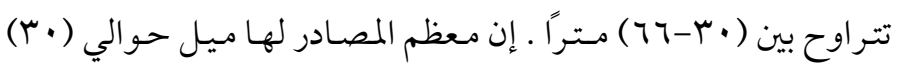

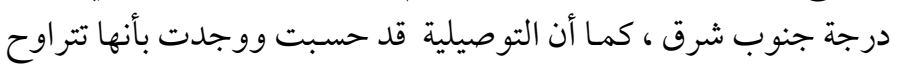
بين (r-r-r) سيمنس. 